\title{
'V-560', NUEVA VARIEDAD PRECOZ DE MAÍZ PARA REGIONES TROPICALES
}

\author{
'V-560', NEW EARLY CORN VARIETY FOR TROPICAL REGIONS
}

\author{
Bulmaro Coutiño-Estrada ${ }^{1 *}$, Noel O. Gómez-Montiel², \\ Gricelda Vázquez-Carrillo ${ }^{3}$ y Víctor A. Vidal-Martínez ${ }^{4}$
}

\begin{abstract}
${ }^{1}$ Campo Experimental Centro de Chiapas, Investigador del Instituto Nacional de Investigaciones Forestales, Agrícolas y Pecuarias ( INIFAP). Km 3 Carr. Ocozocoautla-Cintalapa. Apdo. postal 1. Ocozocoautla, Chiapas. ${ }^{2}$ Campo Experimental Iguala, Investigador del INIFAP. Km 2.5 Carr. Iguala-Tuxpan. Col. Centro. 40000 , Iguala de la Independencia Guerrero, Tuxpan. ${ }^{3}$ Campo Experimental Valle de México, Investigadora del INIFAP. Laboratorio de Calidad de Maíz. Km 13.5 Carr. Reyes-Texcoco. 56250, Coatlinchán, Texcoco, Estado de México. ${ }^{4}$ Campo Experimental Santiago Ixcuintla, Investigador del INIFAP. Km 6 Carr. Internacional México-Nogales, Apartado Postal 100. Santiago Ixcuintla, Nayarit.
\end{abstract}

${ }^{*}$ Autor para correspondencia (coutino.bulmaro@inifap.gob.mx )

En muchas regiones agrícolas del país se cultivan variedades de maíz (Zea mays L.) de polinización libre de diferente ciclo vegetativo; los productores que cultivan variedades de ciclo corto o precoz obtienen grano en menor tiempo que cuando siembran variedades intermedias o tardías, con la ventaja de que pueden sembrar más temprano o más tarde y aprovechar mejor la humedad de la época de lluvias. En 1983, el Campo Experimental Valle del Yaqui (actual Campo Experimental Norman E. Borlaug) del Instituto Nacional de Investigaciones Forestales, Agrícolas y Pecuarias (INIFAP) liberó una variedad de maíz precoz de porte bajo, denominada 'V-424' o 'Tuxpeño Precoz', recomendada para ser cultivada en las regiones tropicales del país con altitudes de hasta $1000 \mathrm{~m}$, desde Sonora hasta Chiapas (Cota et al., 1983), la cual tuvo sus orígenes en la población Tuxpeño crema, originalmente del Centro Internacional de Mejoramiento de Maíz y Trigo. En Chiapas, 'V-424' ha sido muy apreciada por los productores por su precocidad, su planta de porte bajo y por su rendimiento aceptable, razones por las cuales las empresas locales aún producen y comercializan su semilla certificada.

Por ello, el Programa de Mejoramiento Genético de Maíz del Campo Experimental Centro de Chiapas del INIFAP realizó un proceso de mejoramiento genético para renovar esta variedad, el cual se inició en el año 2002 con un grupo de 310 plantas seleccionadas por su porte bajo de planta, periodo corto de floración, tipo de mazorca, sanidad y peso de grano. En estas plantas se aplicó el método de selección combinada de familias de hermanos completos (SCFHC) (Márquez, 1985) durante un periodo de 4 años, mediante el cruzamiento de pares de plantas que coincidieran en tener buenas características fenotípicas y en sus floraciones, para así lograr un mejor control parental en la selección de las familias superiores (Hallauer y Miranda, 1981).

Las evaluaciones de las familias se hicieron en el ciclo agrícola de primavera-verano (PV) (secano o temporal) y las recombinaciones genéticas de las familias superiores en el ciclo agrícola de otoño-invierno (OI) (riego), durante los años $2003 \mathrm{al}$ 2005. Estos experimentos se establecieron en parcelas de productores cooperantes de los municipios de Ocozocoautla, Villaflores, Venustiano Carranza y Jiquipilas, en la región Centro del Estado y en localidades de los municipios de Frontera Hidalgo y Tuxtla Chico en el Soconusco, Estado de Chiapas. Las mejores 10 familias de cada localidad y de toda la región, en cada año, se recombinaron genéticamente mediante polinizaciones manuales para formar variedades nuevas. Al final, 14 variedades experimentales formadas en los tres ciclos de SCFHC, más la variedad original 'V-424', se evaluaron en cuatro localidades durante 2006. En esas evaluaciones destacó la variedad denominada provisionalmente "Coita Ciclo 3" que superó en $9 \%$ el rendimiento de 'V-424' (Coutiño et al., 2008), por lo que en 2012 se le registró en el Servicio Nacional de Inspección y Certificación de Semillas (SNICS) con el nombre de 'V-560', cuyo número de registro definitivo es MAZ-1308-010312.

Las plantas de ' $\mathrm{V}-560$ ' son muy similares a las de 'V-424', ya que ambas variedades son de porte bajo con 1.6 a $2.0 \mathrm{~m}$ de altura (Figura 1), y la mazorca se inserta a una altura de 0.6 a $1.0 \mathrm{~m}$; también son precoces pues su floración media masculina ocurre entre los 51 a $55 \mathrm{~d}$ en el ciclo PV y entre los 65 a $70 \mathrm{~d}$ en el ciclo OI. Las mazorcas son de forma cilíndrica, de 17 a $20 \mathrm{~cm}$ de longitud y 4.1 a $5.0 \mathrm{~cm}$ de diámetro, con 16 a 18 hileras de grano y cada hilera puede tener de 42 a 50 granos; el endospermo es de color blanco cremoso (Figura 1) y de textura semi-dentada, con un contenido de $11.6 \%$ de proteína. El peso hectolítrico del grano es de 77.7 $\mathrm{kg} \mathrm{hL}^{-1}$, por lo que son de primera calidad para la elaboración de tortillas; por cada kilogramo de grano nixtamalizado se obtiene $1.8 \mathrm{~kg}$ de masa y $1.5 \mathrm{~kg}$ de tortilla, las cuales son de agradable color blanco y buena calidad. 


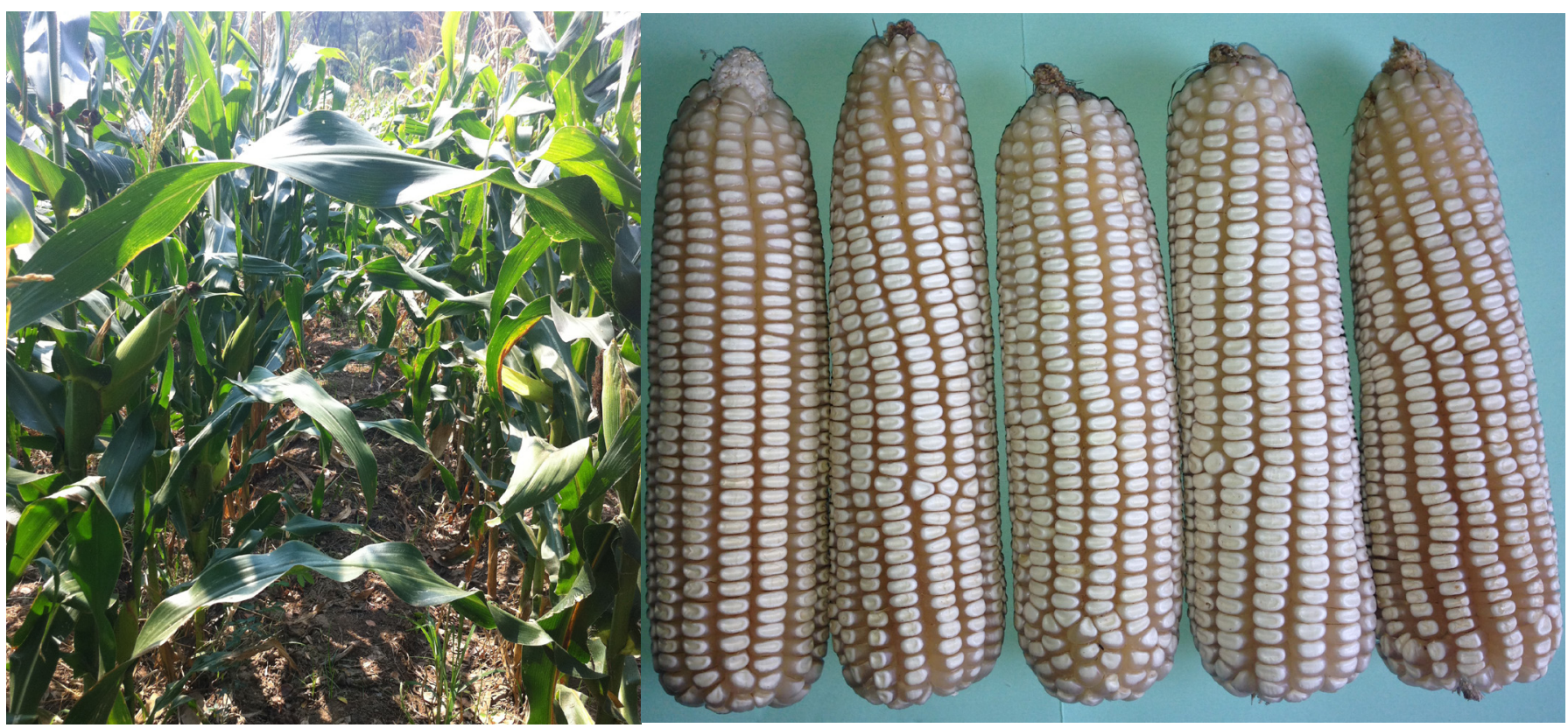

Figura1. Aspecto de planta y mazorca de la variedad precoz de maíz 'V-560' para zonas tropicales.

La variedad ' $\mathrm{V}-560$ ' se evaluó experimentalmente durante los años 2006 a 2007 en siembras de temporal y riego en las principales regiones maiceras de Chiapas. Su índice de cosecha fue de 0.461 , lo que indica que por cada tonelada de rastrojo y mazorca se producen $461 \mathrm{~kg}$ de grano. Los rendimientos promedio en temporal fueron de $4.9 \mathrm{tha}^{-1}$, pero en localidades con buen temporal produjo hasta $5.2 \mathrm{t} \mathrm{ha}^{-1}$; en siembras de riego produjo en promedio $6.5 \mathrm{t} \mathrm{ha}^{-1} \mathrm{y}$ en promedio puede producir casi media tonelada más de grano que 'V-424'. Por su precocidad y su porte bajo de planta, es ideal para siembras tempranas o tardías, se adapta a las irregularidades de la temporada de lluvias y del cambio climático. Esta variedad se puede sembrar tanto en siembras de temporal, de humedad residual (localmente llamadas "tornamil") o de riego, en los municipios de las regiones Centro, Frailesca, Costa y Soconusco del Estado de Chiapas y otras regiones similares de clima cálido seco y cálido subhúmedo del país.

El Campo Experimental Centro de Chiapas tiene semilla original disponible para producir las categorías básica y registrada que requieran las empresas de semilla interesadas en la producción y comercialización de su semilla certificada. Para la producción de semilla de esta categoría se sugiere sembrar a densidades de población de 50,000 plantas ha ${ }^{-1}$, aplicar las recomendaciones del SNICS de aislamiento por espacio o tiempo y eliminar las plantas mezcladas ("desmezcles") de manera oportuna (Coutiño, 1993).

\section{AGRADECIMIENTOS}

A la Fundación Produce Chiapas, A. C., por el financiamiento del Proyecto 2685 "Mejoramiento poblacional de las razas de maíz Comiteco y Tuxpeño para formar variedades mejoradas", el cual apoyó parcialmente los trabajos de mejoramiento genético durante los años 2001 a 2004. También se agradece el apoyo de campo brindado por los M. C. Grisel Sánchez Grajalez y Manuel Grajales Solís.

\section{BIBLIOGRAFÍA}

Cota A. O., R. Valdivia, J. M. Valenzuela, S. Peraza, P. Félix y A. Soqui (1983) V-424, V-425, V-455, V-526, nuevas variedades de maíz de libre polinización para el trópico de México. Folleto Técnico No. 3. Campo Experimental Valle del Yaqui. Instituto Nacional de Investigaciones Forestales, Agrícolas y Pecuarias. Cd. Obregón, Sonora. $25 \mathrm{p}$.

Coutiño E. B. (1993) Normas y técnicas para producir semilla certificada de variedades de maíz. Folleto Técnico No. 7. Campo Experimental Centro de Chiapas. Instituto Nacional de Investigaciones Forestales, Agrícolas y Pecuarias. Ocozocoautla, Chiapas, México. 33 p.

Coutiño E. B., G. Sánchez y V. A. Vidal (2008) Selección entre y dentro de familias de hermanos completos de maíz en Chiapas, México. Revista Fitotecnia Mexicana 31:115-123.

Hallauer A. R. and J. B. Miranda (1981) Quantitative Genetics in Maize Breeding. The Iowa State University Press. Ames, Iowa. 468 p.

Márquez S. F. (1985) Genotecnia Vegetal. Tomo I. Métodos, Teoría, Resultados. Ed. AGT. México, D. F. pp:279-289. 